\title{
Compression of the S1 Nerve Root by an Extradural Vascular Malformation: A Case Report and Discussion of Atypical Causes of Lumbar Radiculopathy
}

\author{
JEFFREY THOMPSON, DO ${ }^{1}$ ROBERT K. MERRILL, MD, ${ }^{2}$ SHEERAZ A. QURESHI, MD ${ }^{3}$ \\ DANTE M. LEVEN, DO ${ }^{1}$ \\ ${ }^{I}$ Department of Orthopedic Surgery, Nassau University Medical Center-East Meadow, New York, ${ }^{2}$ Department of Orthopedic Surgery, Montefiore Medical \\ Center-New York, New York, ${ }^{3}$ Department of Orthopedic Surgery, Hospital for Special Surgery - New York, New York
}

\begin{abstract}
We present a case of lumbar radiculopathy due to a vascular malformation in the lumbar spine and discuss various causes of atypical lumbar radiculopathy. Lumbar radiculopathy is a condition of neurologic deficits and painful symptoms of the lower extremities due to nerve root compression, most commonly at the L5 and S1 levels. Several factors contribute to lumbar radiculopathy, including intervertebral disc herniation, foraminal stenosis, and spinal instability. There are also a number of atypical causes, including medication side effects or metabolic disorders, which produce symptoms of radiculopathy but do not involve compression of the nerve root. Anatomic variations in the nerve roots or vascular supply surrounding the nerve root may also increase the risk of developing radiculopathy and serve as an obstacle to interpreting imaging during a preoperative workup. A 38-year-old woman presented with sudden onset radicular symptoms in her right lower extremity. Lumbar magnetic resonance imaging demonstrated a right-sided L5-S1 extruded nucleus pulposus. Her symptoms failed to improve after conservative management so she underwent surgical decompression of L4-S1. Intraoperatively, we discovered an extensive, extradural vascular malformation present at the L5-S1 level and believed this to be the true cause of her radiculopathy. This case represents an atypical cause of lumbar radiculopathy and demonstrates the importance of considering atypical causes during diagnostic workup and preoperative planning.
\end{abstract}

Lumbar Spine

Keywords: atypical radiculopathy, lumbar radiculopathy

\section{INTRODUCTION}

Lumbar radiculopathy refers to nerve root compression that produces various neurologic deficits in the lower extremities. This condition is listed as 1 of the top 3 common causes of disability in the United States with an incidence of $0.7 \%$ to $9.6 \%$ and a prevalence of $2 \%$ to $8 \%{ }^{1-3}$ The L5 and S1 nerve roots are involved in over $75 \%$ of cases, and the most common etiology is a lumbar intervertebral disc herniation (IDH), though foraminal stenosis, osteophytes, and spinal instability can be contributory causes. ${ }^{4,5}$ Additionally, approximately $80 \%$ of adults will develop back pain at some point in time, though with such a high prevalence, coexisting pathology may be present or involved in the symptomatology. In a study of patients diagnosed with low back pain, the prevalence of sacroiliac joint dysfunction was found to be $15 \%$ to $30 \%{ }^{5}$ Other conditions such as metabolic diseases, medication side effects, infections, or peripheral polyneuropathy can also mimic or coexist with spinal pathology, complicating the diagnostic workup. ${ }^{4}$

In addition to these atypical causes of lumbar radiculopathy, variations in nerve root and vascular anatomy may be present. In a cadaveric study of lumbosacral nerve roots, $14 \%$ of subjects had anomalous variants, most commonly at the L5-S1 level. ${ }^{6}$ Anatomical variants can also challenge the interpretation of imaging studies and if identified will often alter the indicated treatment plan. $^{7}$ With high rates of revision surgery and progression of adjacent level spinal pathology postoperatively, ${ }^{8-10}$ an understanding of these variants is paramount to avoid unnecessary procedures and optimize the preoperative workup. 
This article presents a case of lumbar radiculopathy that was due to a vascular malformation in the lumbar spine at the L5-S1 level.

\section{CASE}

A 38-year-old female presented to the clinic complaining of right lower extremity electrical pain shooting from the right buttocks down to the lateral aspect of the foot. The radicular pain had a sudden onset with no suspected cause or inciting action. She felt the pain constantly and long periods of sitting seemed to aggravate the pain. The symptoms became severe enough that she was unable to continue recreational activities such as running. She denied any motor weakness, balance problems, or bowel and bladder problems. Though she did not try any analgesic medications, she did receive an epidural injection at the L4-5 and L5-S1 levels a few months before presentation without any relief of symptoms. She also had at least 5 pyriformis injections prior to presentation that provided up to $70 \%$ relief of her symptoms. Her initial physical examination was negative for any neurologic deficits of the lower extremities, negative for pain to palpation of the lumbar spine, negative for pain with range of motion of the lumbar spine, and she had a negative straight leg raise. She had magnetic resonance imaging (MRI) done that demonstrated a likely herniated nucleus pulposus on the right side of L5-S1 (Figure 1). A right-sided L5-S1 nerve block relieved her symptoms, indicating the etiology of the pain was nerve root compression and not piriformisrelated sciatica. Over the course of a year, she was managed conservatively with epidural injections and physical therapy. Her symptoms persisted and she developed additional lower back pain. Another MRI, 1 year after the initial MRI, demonstrated persistent herniated pulposus with right-sided and central stenosis at the L5-S1 level (Figure 2). Because of her persistent symptoms and lack of improvement with conservative management, she was indicated for surgical decompression of the L5S1 level. ${ }^{11}$ During the surgery, after the foraminotomy, we noticed a large, extensive vascular malformation on the dura of the L5-S1 junction that was pressed against the S1 nerve root. We continued with the procedure, leaving the malformation intact. The large size of the malformation and proximity to the nerve root made it the most likely etiology of her nerve root compression and resultant radicular symptoms. The foraminotomy

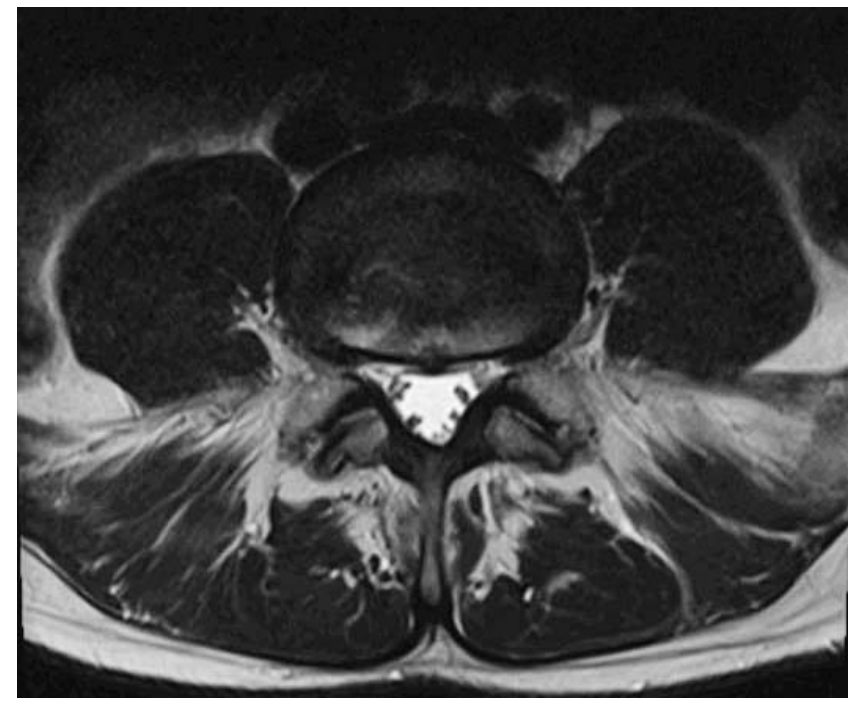

Figure 1. Initial MRI (magnetic resonance imaging) demonstrating herniated nucleus pulposus right L5-S1

successfully relieved the pressure the malformation had on the nerve root, and the patient's symptoms were immediately relieved postoperatively.

\section{DISCUSSION}

This report presents a case of atypical lumbar radiculopathy that appeared to be caused by an IDH based on the clinical course and imaging findings. During the surgical exploration, the disc space was examined, and no notable disc fragment was identified. An extensive vascular malformation surrounding the dorsal dura was visualized and felt to be the cause of the patient's persistent radiculopathy. This report presents this uncommon vascular malformation as a potential cause of lumbar

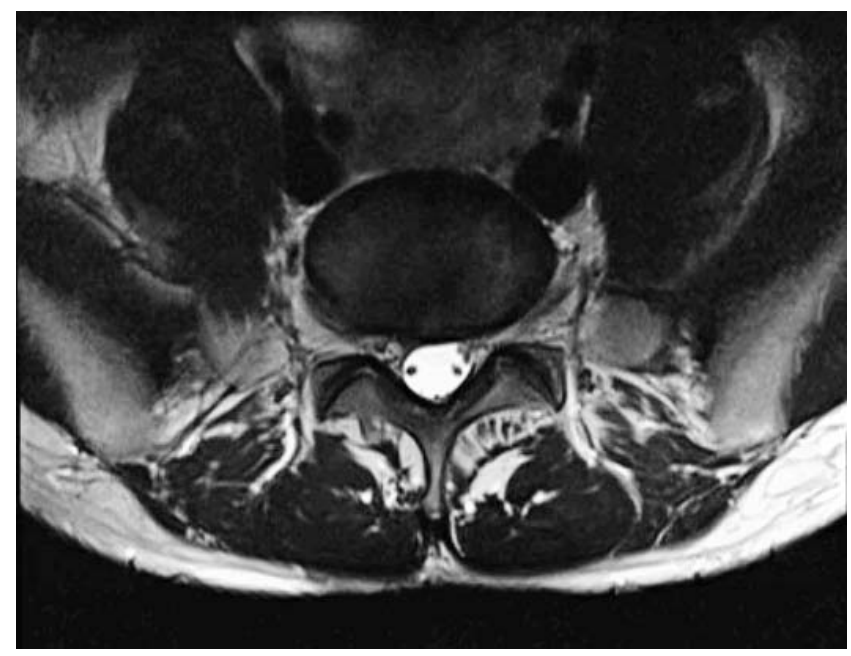

Figure 2. Preoperative MRI (magnetic resonance imaging) demonstrating herniated pulposus with right-sided and central stenosis at the L5-S1 level. 
radiculopathy, a common patient complaint. Furthermore, we review several mimickers of lumbar radiculopathy, which spine surgeons may encounter in clinical practice.

Lumbar radiculopathy is a common condition and most commonly caused by IDH or spinal stenosis in the lower lumbar region. ${ }^{1,2,12,13} \mathrm{IDH}$ more commonly occurs in younger patients $(<50$ years old), whereas stenosis, spondylosis, and other degenerative pathology are more typical in older patients. Several studies have shown that a high percentage of asymptomatic individuals may present with significant pathological findings on imaging. In a classic study by Boden et al, ${ }^{14}$ they found that $57 \%$ of patients over 60 years old had MRI findings of a lumbar disc herniation or spinal stenosis. In a follow-up of these patients, they found that approximately $60 \%$ had a resolution of back pain without treatment with no association between symptoms and initial MRI findings. ${ }^{15}$ Clouding the clinical picture further, IDH can cause a variety of clinical manifestations ranging from back pain to neurologic deficits depending on the timeline, size, and morphology of the disc fragment. A small IDH may cause mild radiculopathy, whereas large herniations can cause a cauda equina type presentation. Therefore, the physician must proceed cautiously with treatment, and a thorough understanding of potential pain generators must be explored.

Pathologic changes of the ipsilateral hip are common in patients with degenerative conditions of the lumbar spine. ${ }^{13}$ Osteoarthritis, osteonecrosis, stress fractures, and femoral acetabular impingement are all common conditions that can usually be diagnosed based on history, risk factors, physical examination, and imaging. ${ }^{16-18}$ The prevalence of hip osteoarthritis is approximately $5 \%$ to $10 \%$, and early signs can often be identified on standing radiographs, whereas osteonecrosis typically develops in patients with specific risk factors (steroid use, alcoholism, trauma) and can also be identified on radiographs or early changes on MRI. Pain from these conditions is more commonly in the groin, though can radiate down the lower extremity and closely mimic an upper lumbar radiculopathy. Greater trochanteric bursitis is a common condition (twice as common in women), which presents as lateral hip pain that can also radiate distally and closely resemble sciatica symptoms. In a review by Tortolani et al, ${ }^{19}$ this condition was found in $20 \%$ of patients presenting with sciatica or spinal pathology. Typically, the symptoms are elicited by direct palpation over the greater trochanter and are not aggravated by tests that irritate an inflamed nerve root such as the straight leg raise or femoral stretch.

Several metabolic, nutritional, and autoimmune conditions can lead to peripheral neuropathy, which may masquerade as radiculopathy. These include diabetes, hypothyroidism, uremia, vitamin B6 and B12 deficiency, malnutrition, alcoholism, rheumatoid arthritis, and lupus erythematosus. Of these, by far the most common are obesity and diabetes, and peripheral neuropathy is a common presentation that affects over $60 \%$ of diabetic patients. ${ }^{20}$ Typically, these patients lose large afferent nerve fibers that provide touch, proprioception, and vibration in a bilateral "stocking-like" distribution due to demyelination. These sensory deficits should be considered in the patient with spinal pathology and concomitant diabetes. Later stages of diabetes include proximal weakness and muscle atrophy, which is less common, though must be evaluated in the older patient with lumbar spinal stenosis or spondylosis and proximal muscular weakness.

Several peripheral sites of nerve compression are frequently encountered in the lower extremities. Meralgia paresthetica is a peripheral neuropathy more common in males with concomitant obesity and diabetes where compression of the lateral femoral cutaneous nerve (LFCN) produces sensory dysesthesias. This may mimic nerve root compression along the L1, 2, or 3 distribution. Tight clothing, obesity, or pregnancy may cause compression that occurs along the fascial tunnel containing the LFCN, which passes under, through, or over the inguinal ligament causing numbness or paresthesias. Occasionally, prolonged prone positioning may cause the same symptoms. Other peripheral compressive neuropathies include peroneal neuropathy, which is most commonly caused by ganglion cysts near the proximal tibio-fibular joint $(30 \%-60 \%)$, and may present similarly to a L4 or L5 radiculopathy. The high incidence $(85 \%)$ of ipsilateral hip abductor weakness due to L4-5 nerve root compression may be overlooked by physicians and can assist in an accurate diagnosis. ${ }^{21}$ Piriformis syndrome is a common finding in patients with symptoms of sciatica due to compression of the nerve exiting the sciatic notch. Patients commonly have unilateral buttock pain, an antalgic gait, pain 
with palpation, and a positive straight leg raise. A positive Pace sign (pain with resisted abduction and external rotation while seated) may be elicited. Other sites of peripheral nerve entrapment include tarsal tunnel syndrome, saphenous nerve compression, and peroneal nerve entrapment and should be considered especially when confronted with a negative lumbar MRI. ${ }^{22-24}$ Electrodiagnostic studies can assist in localizing the site of nerve compression and physical examination findings such as a positive Tinel's sign, pain with palpation, or relief with injections of local anesthetic can further improve diagnostic accuracy.

Radiculopathy may be caused by infectious etiologies such as osteomyelitis or discitis, though more commonly these conditions cause axial pain. ${ }^{25,26}$ Approximately $90 \%$ of patients present with axial pain, though up to $80 \%$ will present with either radiculopathy or a neurologic deficit. Over $60 \%$ will also present with constitutional signs such as fever or chills. Laboratory findings and imaging will further assist in the proper clinical workup. Other rare infectious causes of neuropathy include Guillain-Barre syndrome (GBS), herpes simplex virus, syphilis, tuberculosis, and transverse myelitis (TM). TM occurs in 1 to $5 / 1,000,000$ and causes a demyelination of the spinal cord most commonly at the thoracic level, whereas GBS usually causes acute paresthesias of the hands or feet, which rapidly ascends in a symmetrical pattern. Diagnosis is made by cerebrospinal fluid analysis, imaging, laboratory tests, and clinical presentation, and urgent management in a critical care unit is warranted as these conditions may lead to respiratory failure. Similar clinical findings can also be seen in patients with human immunodeficiency virus (HIV) or due to the side effects to antiretroviral medications. ${ }^{27,28}$ Typically, the neuropathy is a symmetric and distal pattern in patients with high viral loads or low $(<200)$ CD4 counts.

Medications should be considered in the workup of lumbar radiculopathy as several commonly prescribed medications may produce various symptoms involving the neurologic or musculoskeletal systems. Simvastatin is the most commonly prescribed medication in the United States after hydrocodone/acetaminophen and may cause myopathy in approximately $5 \%$ to $10 \%$ of patients. ${ }^{29}$ Myalgias, cramping, and weakness are all common complaints $^{29,30}$ and typically occur at a mean of 6 months after initiation of the medication. Symp- toms usually stop once the medication is terminated. Chemotherapy is another common cause of sensory neuropathy, notably the platinum-containing compounds (cisplatin, carboplatin, and oxaliplatin). Amiodarone may cause sensory neuropathy, and as previously mentioned HIV antiretroviral medications (zalcitabine, didanosine, stavudine) may also cause adverse side effects that are similar to spinal pathology, such as IDH or spinal stenosis. ${ }^{31}$

Spinal arachnoiditis is an important consideration that is defined as adhesions around the arachnoid membrane due to persistent arachnoiditis. This may cause tethering of the spinal cord and alteration of the cranial and intraspinal pressure leading to syringomyelia. ${ }^{32,33}$ Arachnoiditis most commonly occurs postsurgically, though may be caused by infection, subarachnoid hemorrhage, degenerative pathology, TM, postmyelogram, postepidural injection, or following many intradural spinal procedures. ${ }^{34-38}$ Although varying rates of arachnoiditis present following intradural procedures or postsurgically, this should be considered and can be confirmed with MRI or myelogram. MRI is reportedly $99 \%$ accurate, and a staging system has been described by Ross et al. ${ }^{39}$ Most patients present with lumbar radiculopathy, though sensory deficits, back pain, decreased bowel and bladder function, and motor deficits have all been described. ${ }^{39-41}$

Spinal cord arteriovenous malformations (AVM) may exist as arteriovenous fistulas (AVF), first described as "hemorrhoids of the pia mater," and differ from intradural or intraparenchymal vascular malformations. ${ }^{12,42,41}$ Currently, AVMs are classified as type I, dural AVF, type II, glomus or intramedullary $A V M s$, type III, juvenile large intramedullary, extramedullary, and extradural AVMs often over several spinal levels and type IV, intradural extramedullary AVFs arising from the anterior spinal artery or posterior spinal artery as opposed to type I AVFs, which arise from dural branches. $^{44,45}$ These lesions may lead to venous congestion (due to the lack of valves in the coronal venous plexus), decreased perfusion pressure, ischemia, and edema. Ultimately, these changes may produce local pain, radicular pain, sensory changes, weakness, bowel and bladder deficits, or sexual dysfunction. ${ }^{7,46}$ Symptoms typically worsen with time and are often worsened with standing as the venous outflow is directed rostrally. Early reports documented that over $50 \%$ of patients were severely 
disabled by 3 years., ${ }^{7,46}$ The tortuous vessel formations can be visualized on myelography or MRI, commonly along the dorsal surface of the spinal cord, though selective spinal angiography is the study of choice. ${ }^{12}$ Treatment of recognized lesions includes embolization or surgical resection, though both are with inherent risk and a clear delineation of the AVM must be considered to minimize complications. Several methods of opening the dura and arachnoid to release intradural adhesions and sharply dissect the arterialized vein as well as utilization of indocyanine green angiogram intraoperatively have been described. Regardless, recognition of these various types of AVMs is important as they will lead to progressive neurological deficits and may be confused with other types of spinal pathology.

This report highlights a case of lumbar radiculopathy caused by an extradural vascular formation (likely a type I AVM) surrounding the dorsal dura at L5-S1 in a patient with persistent lumbar radiculopathy. The spinal surgeon may encounter this or other atypical causes of radiculopathy, including various types of AVMs and a comprehensive understanding and awareness of these conditions may assist in the proper diagnosis and management of lumbar radiculopathy.

\section{REFERENCES}

1. Freburger JK, Holmes GM, Agans RP, et al. The rising prevalence of chronic low back pain. Arch Intern Med. 2009;169(3):251-258.

2. Zahari Z, Justine M, Dahlan A. Prevalence of low back pain and relationship between risk factors, disability and quality of life among elderly in community. Physiotherapy. 2015;101(supp 1):e1711.

3. Centers for Disease Control and Prevention (CDC). Prevalence and most common causes of disability among adults-United States, 2005.MMWR Morb Mortal Wkly Rep. 2009 May 1;58(16):421-426. https://www.cdc.gov/mmwr/preview/ mmwrhtml/mm5816a2.htm. Accessed May 2017.

4. Rhee JM, Schaufele M, Abdu WA. Radiculopathy and the herniated lumbar disc. Controversies regarding pathophysiology and management. J Bone Joint Surg Am. 2006;88(9):2070-2080.

5. Robinson HS, Brox JI, Robinson R, Bjelland E, Solem S, Telje $\mathrm{T}$. The reliability of selected motion and pain provocation tests for the sacroiliac joint. Man Ther. 2007;12(1):72-79.

6. Kadish LJ, Simmons EH. Anomalies of the lumbosacral nerve roots. An anatomical investigation and myelographic study. J Bone Joint Surg Br. 1984;66(3):411-416.

7. Aminoff MJ, Logue V. The prognosis of patients with spinal vascular malformations. Brain. 1974;97(1):211-218.

8. Jack A, Hardy St-Pierre G, Nataraj A. Adjacent segment pathology: progressive disease course or a product of iatrogenic fusion? Can J Neurol Sci. 2017;44(1):78-82.
9. Yugué I, Okada S, Masuda M, Ueta T, Maeda T, Shiba K. Risk factors for adjacent segment pathology requiring additional surgery after single-level spinal fusion: impact of preexisting spinal stenosis demonstrated by preoperative myelography. Eur Spine J. 2016;25(5):1542-1549.

10. Zhang C, Berven SH, Fortin M, Weber MH. Adjacent segment degeneration versus disease after lumbar spine fusion for degenerative pathology: a systematic review with metaanalysis of the literature. Clin Spine Surg. 2016;29(1):21-29.

11. Lurie JD, Tosteson TD, Tosteson AN, et al. Surgical versus nonoperative treatment for lumbar disc herniation: eight-year results for the spine patient outcomes research trial. Spine (Phila Pa 1976). 2014;39(1):3-16. Erratum in: Spine (Phila Pa 1976). 2015;40(1):E59.

12. Benzel EC. The essentials of spine biomechanics for the general neurosurgeon. Clin Neurosurg. 2003;50:86-177.

13. Grimm BD, Blessinger BJ, Darden BV, Brigham CD, Kneisl JS, Laxer EB. Mimickers of lumbar radiculopathy. $J$ Am Acad Orthop Surg. 2015;23(1):7-17.

14. Boden SD, Davis DO, Dina TS, Patronas NJ, Wiesel SW. Abnormal magnetic-resonance scans of the lumbar spine in asymptomatic subjects. A prospective investigation. $J$ Bone Joint Surg Am. 1990;72(3):403-408.

15. Borenstein DG, O'Mara JW Jr, Boden SD, et al. The value of magnetic resonance imaging of the lumbar spine to predict low-back pain in asymptomatic subjects : a seven-year follow-up study. J Bone Joint Surg Am. 2001;83(9):1306-1311.

16. Dagenais S, Garbedian S, Wai EK. Systematic review of the prevalence of radiographic primary hip osteoarthritis. Clin Orthop Relat Res. 2009;467(3):623-637.

17. Crawford RW, Gie GA, Ling RS, Murray DW. Diagnostic value of intra-articular anaesthetic in primary osteoarthritis of the hip. J Bone Joint Surg Br. 1998;80(2):279281.

18. Seamon J, Keller T, Saleh J, Cui Q. The pathogenesis of nontraumatic osteonecrosis. Arthritis. 2012;2012:601763.

19. Tortolani PJ, Carbone JJ, Quartararo LG. Greater trochanteric pain syndrome in patients referred to orthopedic spine specialists. Spine J. 2002;2(4):251-254.

20. Dyck PJ, Kratz KM, Karnes JL, et al. The prevalence by staged severity of various types of diabetic neuropathy, retinopathy, and nephropathy in a population-based cohort: the Rochester Diabetic Neuropathy Study. Neurology. 1993;43(4):817-824. Erratum in: Neurology. 1993;43(11):2345.

21. Jeon $\mathrm{CH}$, Chung NS, Lee YS, Son KH, Kim JH. Assessment of hip abductor power in patients with foot drop: a simple and useful test to differentiate lumbar radiculopathy and peroneal neuropathy. Spine (Phila Pa 1976). 2013;38(3):257263.

22. Hopayian K, Danielyan A. Four symptoms define the piriformis syndrome: an updated systematic review of its clinical features. Eur J Orthop Surg Traumatol. 2018;28(2):155-164.

23. Hopayian K, Song F, Riera R, Sambandan S. The clinical features of the piriformis syndrome: a systematic review. Eur Spine J. 2010;19(12):2095-2109.

24. Hopayian K, Notley C. A systematic review of low back pain and sciatica patients' expectations and experiences of health care. Spine J. 2014;14(8):1769-1780.

25. Carragee EJ. Pyogenic vertebral osteomyelitis. J Bone Joint Surg Am. 1997;79(6):874-880.

26. Skaf GS, Domloj NT, Fehlings MG, et al. Pyogenic 
spondylodiscitis: an overview. J Infect Public Health. 2010;3(1):516.

27. Kamerman PR, Wadley AL, Cherry CL. HIV-associated sensory neuropathy: risk factors and genetics. Curr Pain Headache Rep. 2012;16(3):226-236.

28. Ngassa Mbenda HG, Wadley A, Lombard Z, Cherry C, Price P, Kamerman P. Genetics of HIV-associated sensory neuropathy and related pain in Africans. $J$ Neurovirol. 2017;23(4):511-519.

29. Brown F, Singer A, Katz A, Konrad G. Statinprescribing trends for primary and secondary prevention of cardiovascular disease. Can Fam Physician. 2017;63(11):e495e503.

30. https://www.uptodate.com/contents/statins-actions-sideeffects-and-administration?search=simvastatin\&source-search_ result\&selectedTitle $=1 \sim 81 \&$ usage_type=default\&display_ rank=1. Robert S Rosenson, MD. Accessed May 2017. Statins: Actions, side effects and administration

31. Pardo CA, McArthur JC, Griffin JW. HIV neuropathy: insights in the pathology of HIV peripheral nerve disease. $J$ Peripher Nerv Syst. 2001;6(1):21-27.

32. McLean DR, Miller JD, Allen PB, Ezzeddin SA. Posttraumatic syringomyelia. J Neurosurg. 1973;39(4):485-492.

33. Savoiardo M. Syringomyelia associated with postmeningitic spinal arachnoiditis. Filling of the syrinx through a communication with the subarachnoid space. Neurology. 1976;26(6 pt 1):551-554.

34. Matsui H, Tsuji H, Kanamori M, Kawaguchi Y, Yudoh K, Futatsuya R. Laminectomy-induced arachnoradiculitis: a postoperative serial MRI study. Neuroradiology. 1995;37(8):660666.

35. Todeschi J, Chibbaro S, Gubian A, Pop R, Proust F, Cebula H. Spinal adhesive arachnoiditis following the rupture of an Adamkiewicz aneurysm: literature review and a case illustration. Neurochirurgie. 2018;64(3):177-182.

36. Brodbelt AR, Stoodley MA. Syringomyelia and the arachnoid web. Acta Neurochir (Wien). 2003;145(8):707-711; discussion 711.

37. Benner B, Ehni G. Spinal arachnoiditis. The postoperative variety in particular. Spine (Phila Pa 1976). 1978;3(1):40-44.

38. Guyer DW, Wiltse LL, Eskay ML, Guyer BH. The longrange prognosis of arachnoiditis. Spine (Phila Pa 1976). 1989;14(12):1332-1341.

39. Ross JS, Delamarter R, Hueftle MG, et al. Gadolinium-
DTPA-enhanced MR imaging of the postoperative lumbar spine: time course and mechanism of enhancement. AJR Am J Roentgenol. 1989;152(4):825-834.

40. Roca J, Moreta D, Ubierna MT, Cáceres E, Gómez JC. The results of surgical treatment of lumbar arachnoiditis. Int Orthop. 1993;17(2):77-81.

41. Shikata J, Yamamuro T, Iida H, Sugimoto M. Surgical treatment for symptomatic spinal adhesive arachnoiditis. Spine (Phila Pa 1976). 1989;14(8):870-875.

42. Gaupp J. Hämorrhoiden der Pia Mater Spinalis im Gebiet des Lendenmarks. Beitr Pathol. 1888;2:516-518.

43. Delamarter RB, Ross JS, Masaryk TJ, Modic MT, Bohlman HH. Diagnosis of lumbar arachnoiditis by magnetic resonance imaging. Spine (Phila Pa 1976). 1990;15(4):304-310.

44. Zozulya YP, Slin'ko EI, Al-Qashqish II. Spinal arteriovenous malformations: new classification and surgical treatment. Neurosurg Focus. 2006;20(5):E7.

45. Heros RC, Debrun GM, Ojemann RG, Lasjaunias PL, Naessens PJ. Direct spinal arteriovenous fistula: a new type of spinal AVM. Case report. J Neurosurg. 1986;64(1):134-139.

46. Simopoulos TT, Manchikanti L, Singh V, et al. A systematic evaluation of prevalence and diagnostic accuracy of sacroiliac joint interventions. Pain Physician. 2012;15(3):E305E344.

Disclosures and COI: The authors received no funding for this study and report no conflicts of interest.

Corresponding Author: Jeffrey Thompson, DO, 2201 Hempstead Turnpike, 6th Floor, Department of Orthopedics, East Meadow, NY 11554. Phone: (516) 572-6703; Fax: (516) 572-0024. Email: jthomps4@numc.edu.

Published 29 February 2020

This manuscript is generously published free of charge by ISASS, the International Society for the Advancement of Spine Surgery. Copyright (c) 2020 ISASS. To see more or order reprints or permissions, see http://ijssurgery.com. 